\section{Dr. Wallace and Dr. Stone reply}

\section{To the Editor:}

We appreciate the experience that Wendling and colleagues have shared ${ }^{1}$. Relapsing polychondritis (RP) is a difficult condition to manage and its rarity limits our ability to study the disease and to optimize treatment strategies. Numerous reviews and case reports have cited varying success with a number of treatment strategies, but predicting which patients will respond to which treatment has been challenging. The heterogeneity of responses suggests that RP is composed of disease subsets that have distinctive pathophysiologies and natural histories. The same heterogeneity of response holds true for the use of tocilizumab (TCZ), as demonstrated by the therapeutic failure in Dr. Wendling's patient.

That patient's experience highlights some important features of TCZ and RP. The normalization of the CRP suggests that interleukin 6 receptor (IL-6R) inhibition with TCZ was successful, but the persistence of symptoms raises the possibility that an alternative inflammatory pathway contributed to disease. A possibility is that higher doses of TCZ were required in this patient to control the disease.

The authors raise the question of the usefulness of measuring serum IL-6 levels to predict response to TCZ, but the role for such assays remains unclear, as discussed by Nishimoto, et $a l^{2}$. Immunosuppressive medications such as glucocorticoids may lower serum IL-6 concentrations and dissuade physicians from using TCZ, yet some patients still derive important benefits from TCZ in that setting and are able to discontinue glucocorticoids after the start of targeted IL- 6 receptor blockade. In addition, because the serum IL-6 level typically increases substantially following the administration of TCZ (because of decreased receptor-mediated clearance), serial levels appear to be less useful once IL-6 receptor blockade has been initiated. Future studies may investigate the cytokine profiles of patients before and after treatment with a variety of agents, to better understand both the disease and the treatment.

ZACHARY S. WALLACE, MD; JOHN H. STONE, MD, MPH, Massachusetts General Hospital and Harvard Medical School, Division of Rheumatology, Allergy, and Immunology, 55 Fruit Street, Yawkey 2C, Boston, Massachusetts 02114, USA. Address correspondence to Dr.

Stone; E-mail: jhstone@partners.org

\section{REFERENCES}

1. Wendling D, Godfrin-Valnet M, Prati C. Treatment of relapsing polychondritis with tocilizumab [letter]. J Rheumatol 2013;40:1233.

2. Nishimoto N, Terao K, Mima T, Nakahara H, Takagi N, Kakehi T. Mechanisms and pathologic significances in increase in serum interleukin-6 (IL-6) and soluble IL-6 receptor after administration of an anti-IL-6 receptor antibody, tocilizumab, in patients with rheumatoid arthritis and Castleman disease. Blood 2008; 112:3959-64.

J Rheumatol 2013;40:7; doi:10.3899/jrheum.130420 